\title{
Quantitative Evaluation of Medial Temporal Lobe Morphology in Children with Febrile Status Epilepticus: Results of the FEBSTAT Study
}

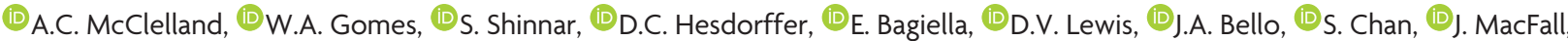

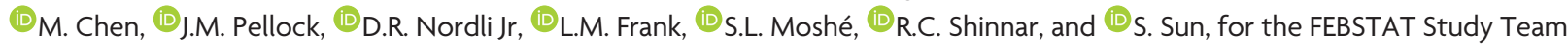

\begin{abstract}
BACKGROUND AND PURPOSE: The pathogenesis of febrile status epilepticus is poorly understood, but prior studies have suggested an association with temporal lobe abnormalities, including hippocampal malrotation. We used a quantitative morphometric method to assess the association between temporal lobe morphology and febrile status epilepticus.
\end{abstract}

MATERIALS AND METHODS: Brain MR imaging was performed in children presenting with febrile status epilepticus and control subjects as part of the Consequences of Prolonged Febrile Seizures in Childhood study. Medial temporal lobe morphologic parameters were measured manually, including the distance of the hippocampus from the midline, hippocampal height:width ratio, hippocampal angle, collateral sulcus angle, and width of the temporal horn.

RESULTS: Temporal lobe morphologic parameters were correlated with the presence of visual hippocampal malrotation; the strongest association was with left temporal horn width $(P<.001$; adjusted $O R, 10.59)$. Multiple morphologic parameters correlated with febrile status epilepticus, encompassing both the right and left sides. This association was statistically strongest in the right temporal lobe, whereas hippocampal malrotation was almost exclusively left-sided in this cohort. The association between temporal lobe measurements and febrile status epilepticus persisted when the analysis was restricted to cases with visually normal imaging findings without hippocampal malrotation or other visually apparent abnormalities.

CONCLUSIONS: Several component morphologic features of hippocampal malrotation are independently associated with febrile status epilepticus, even when complete hippocampal malrotation is absent. Unexpectedly, this association predominantly involves the right temporal lobe. These findings suggest that a spectrum of bilateral temporal lobe anomalies are associated with febrile status epilepticus in children. Hippocampal malrotation may represent a visually apparent subset of this spectrum.

ABBREVIATIONS: EEG = electroencephalography; FEBSTAT = Consequences of Prolonged Febrile Seizures in Childhood; FSE = febrile status epilepticus; HIMAL = hippocampal malrotation; $\mathrm{SFS}=$ simple febrile seizure

$\mathbf{P}$ rolonged febrile seizures are associated with subsequent development of epilepsy, whereas brief febrile seizures are not. ${ }^{1}$ The factors that predispose to prolonged febrile seizures are there-

Received May 19, 2016; accepted after revision July 4.

From Departments of Radiology (A.C.M., W.A.G., J.A.B.), Neurology (S. Shinnar, S.L.M., R.C.S.), Pediatrics (S. Shinnar, S.L.M.), Epidemiology and Population Health (S. Shinnar), and Neuroscience (S.L.M.), Montefiore Medical Center, Albert Einstein College of Medicine, Bronx, New York; Departments of Epidemiology (D.C.H. M.C.) and Radiology (S.C.), Gertrude H. Sergievsky Center, Columbia University, New York, New York; Department of Health Evidence and Policy (E.B.), Mount Sinai School of Medicine, New York, New York; Departments of Pediatrics (Neurology) (D.V.L.) and Radiology (J.M.), Duke University Medical Center, Durham, North Carolina; Departments of Neurology (J.M.P.) and Biostatistics (S. Sun), Medical College of Virginia, Virginia Commonwealth University, Richmond, Virginia; Department of Neurology (D.R.N.), Ann \& Robert H. Lurie Children's Hospital of Chicago, Chicago, Illinois; and Department of Neurology (L.M.F.), Children's Hospital of The King's Daughters and Eastern Virginia Medical School, Norfolk, Virginia.

This work was supported by the National Institute of Neurological Disorders and Stroke grant 2R37 NS43209 (Principal Investigator: S. Shinnar, MD, PhD) and the National Institute of Child Health and Human Development grant 36867 (Principal Investigator: D.C. Hesdorffer, PhD). fore of profound interest but are not well-understood. The Consequences of Prolonged Febrile Seizures in Childhood (FEBSTAT) study is a prospective multicenter trial studying children who presented with febrile status epilepticus (FSE), defined as febrile seizures lasting longer than 30 minutes, in comparison with a control group consisting of children presenting with brief, simple febrile seizures. ${ }^{2}$ The initial evaluation of subjects in the FEBSTAT study identified several risk factors for FSE, including the morphologic anomaly hippocampal malrotation (HIMAL). ${ }^{3,4}$ While these findings suggest a relationship between a medial tem-

Paper previously presented in abstract form at: Annual Meeting of the American Society of Neuroradiology and the Foundation of the ASNR Symposium, April 25-30, 2015; Chicago, Illinois.

Please address correspondence to William A. Gomes, MD, PhD, Division of Neuroradiology, Department of Radiology, Montefiore Medical Center, 111 East 210th St, Bronx, NY 10467; e-mail: wgomes@montefiore.org

- Indicates open access to non-subscribers at www.ajnr.org

http://dx.doi.org/10.3174/ajnr.A4919 
poral lobe anatomic variation and FSE, the precise nature and extent of this relationship are not clear.

Medial temporal lobe structural anatomy is the result of a complex developmental process in which the medial temporal lobe cortex infolds and rotates around the hippocampal gyrus. ${ }^{5,6}$ Qualitative descriptions of abnormal hippocampal morphology have been reported in a number of pathologic conditions, including temporal lobe epilepsy, both as an isolated finding ${ }^{7}$ and in association with other developmental abnormalities. ${ }^{8} \mathrm{HIMAL}$ is a specific anomaly of hippocampal development, which has also been described by other terms, including "incomplete hippocampal inversion." ${ }^{7}$ Published criteria for HIMAL vary slightly among reports but include an abnormally rounded, "globular" configuration of the hippocampus on coronal images, blurring of internal hippocampal architecture, an abnormally medial location of the hippocampus, vertical orientation of the collateral sulcus, and enlargement of the temporal horn of the lateral ventricle (apparently reflecting medial displacement of the hippocampus).

Visual interpretation of scans obtained in FEBSTAT revealed an increased incidence of HIMAL in subjects presenting with FSE relative to control subjects, establishing HIMAL as a risk factor for FSE. ${ }^{9}$ However, the specific morphologic features of HIMAL that are most associated with prolonged febrile seizures remain undefined. In addition, a substantial majority of scans in children with febrile seizures from the FEBSTAT study demonstrated no abnormality on visual interpretation. It is unclear what role the variation in medial temporal lobe morphology may play in these visually healthy subjects.

The goal of this study was to elucidate the relationship between medial temporal lobe morphology and prolonged febrile seizures by performing a quantitative analysis of medial temporal lobe morphology in subjects from the FEBSTAT study. We address 3 primary questions: 1) Does the visual interpretation of HIMAL by experienced interpreters reflect quantitative variation in underlying temporal lobe morphology? 2) Of the individual morphologic features of HIMAL, which are most strongly associated with FSE? 3) In subjects without HIMAL or other overt abnormal findings, does subtle variation in temporal lobe morphology predict FSE?

\section{MATERIALS AND METHODS}

\section{Subject Groups and Imaging}

Cohort selection, patient recruitment, and imaging procedures for the FEBSTAT study have been described in detail previously. ${ }^{2,9,10}$ All procedures were approved by the Institutional Review Board for the Protection of Human Subjects at all participating institutions. Written informed consent was obtained from the parents of all subjects. FSE was defined as a provoked seizure in which the sole acute provocation was fever (temperature of $>38.4^{\circ} \mathrm{C}, 101.0^{\circ} \mathrm{F}$ ) without a prior history of afebrile seizures and without evidence of an acute CNS infection or insult. ${ }^{11}$ The 226 subjects with FSE in this study were enrolled from 3 prospective studies as described previously ${ }^{12}: 191$ from the FEBSTAT cohort, ${ }^{9}$ 23 from the Duke FEBSTAT pilot study, ${ }^{13}$ and 12 from the Columbia first febrile seizure study. ${ }^{14}$ A control group of 96 children who presented with a simple febrile seizure (SFS) and who underwent baseline MR imaging similar to those with FSE was also obtained from the Columbia study. ${ }^{14}$ SFSs are febrile seizures lasting
$<10$ minutes without focal features and without recurrence during the febrile illness. ${ }^{15}$

In patients with FSE, $67 \%$ of scans were obtained within 3 days of presentation and $88 \%$ were obtained within 7 days. ${ }^{9}$ Seizure classification was performed by review of source documents by a central phenomenology core blinded to electroencephalography (EEG) and MR imaging findings. ${ }^{2}$ MR imaging sequences have been described in detail previously ${ }^{9,10}$ and included coronal oblique T2-weighted fast spin-echo sequences. All scans were performed at 1.5T. Visual analysis of MRIs was performed by 2 experienced American Board of Radiology-certified radiologists (J.A.B. and S.C.) with Certificates of Advanced Qualification in neuroradiology. MR imaging readers were informed of the subject's age at the time of the examination but were blinded to all other clinical parameters. HIMAL was scored as negative for HIMAL, left HIMAL, bilateral HIMAL, or equivocal. Hippocampal T2 signal was scored from 0 to 4 with $0=$ normal, $1=$ equivocal, $2=$ mildly abnormal T2 signal on $\geq 1$ section, $3=$ moderately abnormal, and $4=$ markedly abnormal findings throughout the hippocampus. All studies were read independently, but discordant reads were discussed for consensus. For this study, visually normal cases were those in which HIMAL was scored as negative for HIMAL and T2 signal was scored as zero. The results of the initial qualitative analysis from the baseline MR imaging scans have been reported previously. ${ }^{9}$

\section{Quantitative Image Analysis}

Quantitative evaluation of bilateral medial temporal lobe morphology was performed by manual measurement of predetermined structures of interest on a T2-weighted coronal oblique image at the level of the cerebral aqueduct. All measurements were performed blinded to all clinical data except patient age. The measurement strategy is illustrated in Fig 1. The subject's midline was defined as a line through the cerebral aqueduct. Unless otherwise specified, measurements were performed parallel to the horizontal axis of the patient, defined as a line orthogonal to the subject's midsagittal plane. Hippocampal shape was evaluated by calculating the ratio of hippocampal height to width. The medial aspect of the hippocampus was defined as the point at the most medial extent of the hippocampal body as distinct from the subiculum. The width of the hippocampus was defined by extending the longest line possible from the medial aspect of the hippocampus laterally to the border of the hippocampus and the temporal horn CSF. The hippocampal height was defined as the greatest extent of the hippocampal body orthogonal to the line defining the hippocampal width.

The medial/lateral location of the hippocampus was evaluated at both the medial aspect of the hippocampus by the distance of the hippocampus from midline and at the lateral aspect of the hippocampus by the width of the temporal horn of the lateral ventricle. The distance of the hippocampus from midline was determined by measuring the distance from the subject's midline to the medial aspect of the hippocampus. To account for differences in brain size, we normalized this distance of the hippocampus from the midline to the distance of the uncus from midline, defined on the same image as the distance from the midline to the most medial aspect of the temporal lobe. The width of the temporal horn of the lateral ventricle was defined as the distance from

AJNR Am J Neuroradiol 37:2356-62 Dec 2016 www.ajnr.org 

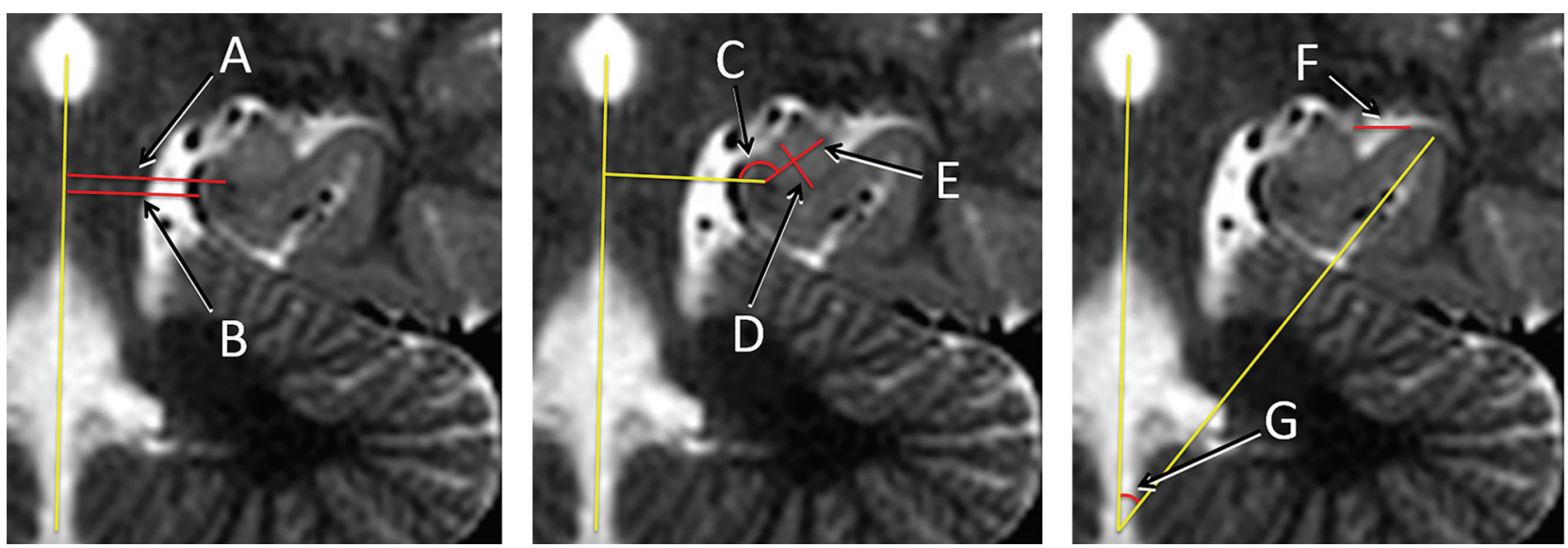

FIG 1. Medial temporal lobe morphologic measurements. Linear and angular measurements, shown in red, were obtained in relation to reference lines, shown in yellow. Measurements were obtained bilaterally; right-sided measurements are omitted here for clarity. Note the presence of HIMAL in this subject. $A$ and $B$, Distances of the hippocampal formation and uncus from the midline. C, Angle of the hippocampal formation. $D$ and $E$, Height and width of the hippocampal formation. $F$, Width of the temporal horn. $G$, Angle of the collateral sulcus.

the most lateral aspect of the hippocampus to the most lateral aspect of the lateral CSF space. If a thin curvilinear CSF space extended from the lateral aspect of the temporal horn around the collateral eminence (Fig 1), this region was not included in the temporal horn width.

Hippocampal rotation was evaluated by determining the angles of the hippocampus and the collateral sulcus. The angle of the hippocampus was defined as the angle of the line defining the hippocampal width as described above relative to the subject's horizontal axis. The collateral sulcus angle was determined with a single line drawn through the middle of the collateral sulcus relative to the subject's midline.

HIMAL is reportedly associated with blurring of the internal hippocampal architecture. However, the internal hippocampal architecture is not reliably demonstrated in young children at $1.5 \mathrm{~T}$, the magnet strength used in most of the FEBSTAT cohort at initial presentation. This component of HIMAL therefore could not be assessed in this study.

Scans in which accurate and comparable measurements could not be made due to imaging factors such as artifacts, patient rotation, or section selection were not included in this analysis. Of the 226 subjects with FSE and 96 subjects with SFS described above, 33 subjects with FSE and 4 subjects with SFS were excluded due to imaging features, for a final analysis of 193 subjects with FSE and 92 subjects with SFS. In most cases, all measurements were made from a single image. In several cases, one or both of the collateral sulci could not be identified on the chosen image. If the collateral sulcus could be identified on an adjacent section, this measurement was included. If not, a collateral sulcus measurement was not included for that subject. The left collateral sulcus measurement was not obtained for 17 subjects, and the right collateral sulcus measurement was not obtained for 8 subjects. In addition, right-sided measurements were not included for a single case in which a choroidal fissure cyst distorted the right medial temporal lobe anatomy.

\section{Statistical Analysis}

All analyses were performed in SAS 9.4 (SAS Institute, Cary, North Carolina), and $P$ values $\leq .05$ were considered statistically
Table 1: Descriptive summary of the MRI measurements

\begin{tabular}{lccc}
\hline \multicolumn{1}{c}{ Measurement } & No. & Mean & SD \\
\hline Left side & & & \\
Collateral sulcus angle $\left(^{\circ}\right)$ & 268 & 61.9534 & 12.3098 \\
Lateral ventricle width $(\mathrm{cm})$ & 285 & 0.3604 & 0.2053 \\
Hipp angle $\left(^{\circ}\right.$ ) & 285 & 174.4526 & 12.5996 \\
Hipp height:width & 285 & 0.7129 & 0.1106 \\
Hipp distance from midline & 285 & 1.5141 & 0.217 \\
Right side & & & \\
Collateral sulcus angle $\left(^{\circ}\right)$ & 277 & 68.9564 & 9.6766 \\
Lateral ventricle width $(\mathrm{cm})$ & 284 & 0.257 & 0.158 \\
Hipp angle $\left({ }^{\circ}\right.$ ) & 284 & 184.1936 & 9.0709 \\
Hipp height:width & 284 & 0.6862 & 0.0919 \\
Hipp distance from midline & 284 & 1.5267 & 0.2166 \\
\hline
\end{tabular}

Note:-Hipp indicates hippocampal.

significant. Descriptive statistics for all MR imaging measurements were generated (Table 1). Univariate statistical comparisons were performed between the MR imaging measures and both HIMAL (present versus absent) and seizure duration (SFS versus FSE). Multivariate statistical analyses of the MR imaging data were then performed. Cutoff measurements were determined by conducting univariate logistic regression for each of the MR imaging measurements separately, with a binary outcome variable. This analysis was performed separately by using as the outcome variable either the consensus determination of HIMAL (present versus absent) or the subject's seizure duration (FSE versus SFS). The optimal cutoff point was obtained for each of the measurements by selecting the one resulting in the maximum sum of sensitivity and specificity (the Youden index) ${ }^{16}$ for the outcome variable. From this, a dummy variable was created for each of the MR imaging measurements on the basis of the corresponding cutoffs. Values at or below the cutoff were the reference for each measurement. Univariate logistic analysis was repeated with the newly created dummy variables. Multivariate logistic regression analyses were then fit with all $5 \mathrm{MR}$ imaging dummy variables. This step was performed separately for each side (left and right) for the seizure-duration outcome variable. A similar analysis was conducted with seizure duration (FSE versus SFS) as the outcome variable. 
Table 2: Association between left hippocampal quantitative morphology and HIMAL

\begin{tabular}{lrcccccc}
\multicolumn{1}{c}{ Measurement } & Cutoff & Sensitivity & Specificity & $\begin{array}{c}\text { Unadjusted OR } \\
(\mathbf{9 5 \%} \mathrm{Cl})\end{array}$ & $\begin{array}{c}\boldsymbol{P} \\
\text { Value }\end{array}$ & $\begin{array}{c}\text { Adjusted OR } \\
(\mathbf{9 5 \%} \mathrm{Cl})\end{array}$ & $\begin{array}{c}\boldsymbol{P} \\
\text { Value }\end{array}$ \\
\hline Collateral sulcus angle $\left(^{\circ}\right)$ & 56.26 & 0.5789 & 0.7355 & $0.26(0.10-0.68)$ & .0059 & \\
Lateral ventricle width $(\mathrm{cm})$ & 0.53 & 0.8421 & 0.861 & $33.04(9.16-119.11)$ & $<.0001$ & $10.59(2.65-42.34)$ & .0009 \\
Hipp angle $\left(^{\circ}\right)$ & 178.37 & 0.8421 & 0.4595 & $0.22(0.06-0.78)$ & .0184 & & \\
Hipp height:width & 0.75 & 0.6842 & 0.7181 & $5.52(2.02-15.07)$ & .0009 & $3.69(1.11-12.24)$ & .0332 \\
Hipp distance from midline & 1.42 & 0.8947 & 0.6988 & $0.05(0.01-0.23)$ & $<.0001$ & $0.12(0.02-0.59)$ & .0094 \\
\hline
\end{tabular}

Table 3: Association between quantitative temporal lobe morphology and FSE

\begin{tabular}{|c|c|c|c|c|c|c|c|}
\hline Measurement & Cutoff & Sensitivity & Specificity & $\begin{array}{c}\text { Unadjusted OR } \\
(95 \% \mathrm{Cl})\end{array}$ & $\begin{array}{c}P \\
\text { Value }\end{array}$ & $\begin{array}{c}\text { Adjusted OR } \\
(95 \% \mathrm{CI})\end{array}$ & $\begin{array}{c}P \\
\text { Value }\end{array}$ \\
\hline \multicolumn{8}{|l|}{ Left side } \\
\hline Collateral sulcus angle $\left({ }^{\circ}\right)$ & 70.68 & 0.3017 & 0.7977 & $1.70(0.93-3.13)$ & .0858 & $1.73(0.91-3.32)$ & .0971 \\
\hline Lateral ventricle width (cm) & 0.17 & 0.8756 & 0.2609 & $2.49(1.32-4.68)$ & .0048 & $2.79(1.39-5.59)$ & .0038 \\
\hline Hipp angle $\left({ }^{\circ}\right)$ & 183.66 & 0.8394 & 0.2391 & $0.61(0.33-1.13)$ & .1133 & $0.62(0.31-1.23)$ & .168 \\
\hline Hipp height:width & 0.61 & 0.1658 & 0.913 & $0.48(0.21-1.09)$ & .0781 & $0.46(0.20-1.08)$ & .0756 \\
\hline Hipp distance from midline & 1.51 & 0.4922 & 0.6196 & $1.58(0.95-2.62)$ & .0774 & $1.69(0.96-2.99)$ & .0714 \\
\hline \multicolumn{8}{|l|}{ Right side } \\
\hline Collateral sulcus angle $\left({ }^{\circ}\right)$ & 71.35 & 0.4785 & 0.6593 & $1.78(1.06-2.99)$ & .0305 & $1.87(1.05-3.34)$ & .0351 \\
\hline Lateral ventricle width $(\mathrm{cm})$ & 0.20 & 0.6198 & 0.6087 & $2.54(1.52-4.22)$ & .0003 & $4.56(2.48-8.41)$ & $<.0001$ \\
\hline Hipp angle $\left({ }^{\circ}\right)$ & 185.50 & 0.5052 & 0.6739 & $2.11(1.26-3.55)$ & .0049 & $2.26(1.26-4.05)$ & .0065 \\
\hline Hipp height:width & 0.66 & 0.651 & 0.4891 & $1.79(1.08-2.96)$ & .0244 & $2.06(1.17-3.61)$ & .0119 \\
\hline Hipp distance from midline & 1.52 & 0.4948 & 0.663 & $1.93(1.15-3.23)$ & .0128 & $2.29(1.23-4.25)$ & .0091 \\
\hline
\end{tabular}

Table 4: Association between quantitative temporal lobe morphology and FSE in visually normal subjects

\begin{tabular}{|c|c|c|c|c|c|c|c|}
\hline Measurement & Cutoff & Sensitivity & Specificity & $\begin{array}{c}\text { Unadjusted OR } \\
(95 \% \mathrm{CI})\end{array}$ & $\begin{array}{c}P \\
\text { Value }\end{array}$ & $\begin{array}{c}\text { Adjusted OR } \\
(95 \% \mathrm{CI})\end{array}$ & $\begin{array}{c}P \\
\text { Value }\end{array}$ \\
\hline \multicolumn{8}{|l|}{ Left side } \\
\hline Collateral sulcus angle $\left({ }^{\circ}\right)$ & 70.65 & 0.3247 & 0.7931 & $1.84(0.99-3.42)$ & .0529 & $1.83(0.95-3.55)$ & .0715 \\
\hline Lateral ventricle width $(\mathrm{cm})$ & 0.17 & 0.8631 & 0.2667 & $2.29(1.21-4.34)$ & .0113 & $2.61(1.29-5.31)$ & .0078 \\
\hline Hipp angle $\left({ }^{\circ}\right)$ & 183.66 & 0.8394 & 0.2391 & $0.66(0.35-1.24)$ & .195 & $0.62(0.30-1.28)$ & .1947 \\
\hline Hipp height:width & 0.61 & 0.1667 & 0.9111 & $0.49(0.21-1.12)$ & .0907 & $0.44(0.18-1.04)$ & .0604 \\
\hline Hipp distance from midline & 1.51 & 0.5298 & 0.6111 & $1.77(1.05-2.98)$ & .0317 & $1.90(1.06-3.42)$ & .0315 \\
\hline \multicolumn{8}{|l|}{ Right side } \\
\hline Collateral sulcus angle $\left(^{\circ}\right)$ & 71.35 & 0.4731 & 0.6556 & $1.71(1.01-2.904)$ & .0478 & $1.746(0.97-3.15)$ & .0636 \\
\hline Lateral ventricle width $(\mathrm{cm})$ & 0.20 & 0.593 & 0.6158 & $2.33(1.39-3.923)$ & .001 & $4.07(2.18-7.58)$ & $<.0001$ \\
\hline Hipp angle $\left({ }^{\circ}\right)$ & 185.49 & 0.5233 & 0.6813 & $2.35(1.38-4.00)$ & .0049 & $2.43(1.33-4.42)$ & .0038 \\
\hline Hipp height:width & 0.70 & 0.4419 & 0.7033 & 1.88 (1.09-3.22) & .0227 & $1.81(1.002-3.28)$ & .0494 \\
\hline Hipp distance from midline & 1.52 & 0.4942 & 0.6593 & $1.89(1.18-3.20)$ & .0177 & $2.062(1.10-3.87)$ & .0245 \\
\hline
\end{tabular}

\section{RESULTS}

\section{Relationship of Medial Temporal Lobe Morphology to Visual HIMAL}

Descriptive statistics for the 5 bilateral measurements are detailed in Table 1. To determine whether our quantitative evaluation of medial temporal lobe morphology captured the subjective differences in cases identified as HIMAL, we first evaluated the relationship between medial temporal lobe morphology and visual HIMAL. Because HIMAL was almost exclusively identified on the left side, we analyzed the relationship between left-sided measurements and cases read as either left-sided HIMAL or bilateral HIMAL. The cutoff values for left-sided measurements that maximize the Youden index for distinguishing cases with and without left-sided HIMAL are detailed in Table 2. Univariate logistic regression analysis using these cutoff values revealed significant associations between each of the 5 left-sided measurements and the presence of left-sided HIMAL (Table 2). In the final multivariate model, HIMAL was associated with an increased left lateral ventricle width $(>0.5283 \mathrm{~cm}, P=.0009)$, and a "rounder" hippocampus (hippocampal height:width ratio of $>0.7502 \mathrm{~cm}, P=$
.0332). A negative relationship was seen between HIMAL and the distance of the hippocampus from the midline, with a value of this distance normalized to the distance of the uncus from the midline of $>1.4236(P=.0094)$. Although HIMAL was associated with a more vertical angle of the left hippocampus $\left(178.4^{\circ}, P=.0184\right)$ and a more vertical orientation of the collateral sulcus $\left(56.26^{\circ}\right.$, $P=.0059)$ in the univariate logistic regression analysis, these relationships were not significant in the multivariate logistic regression analysis.

\section{Relationship of Medial Temporal Lobe Morphology to Seizure Duration}

We next evaluated the relationship between medial temporal lobe morphology and seizure duration, by using a multivariate model approach similar to that used for comparison of MR imaging measurements with the HIMAL. The cutoffs for temporal lobe measurements to maximize the Youden index for distinguishing FSE and SFS are detailed in Table 3. In both univariate and multivariate logistic regression analysis, we found a significant relationship between increased width of the left lateral ventricle and 
FSE (Table 3). In the multivariate analysis, a left lateral ventricle width of $>0.169 \mathrm{~cm}$ was associated with FSE $(P=.0038)$. We also observed a relationship between multiple right-sided measurements and FSE (Table 3). In the multivariate logistic regression model, FSE was associated with the width of the right lateral ventricle of $>0.202 \mathrm{~cm}(P<.0001)$, normalized distance of the right hippocampus from the midline of $1.523(P=.0091)$, ratio of right hippocampal height:width of $0.660(P=.0119)$, right collateral sulcus angle of $71.35^{\circ}(P=.0351)$, and right hippocampal angle of $185.5^{\circ}(P=.0065)$. Univariate $t$ tests were also performed to compare group means for the temporal lobe measurements. No significant difference was observed in this analysis; $P$ values approaching significance were observed for the normalized distance of the right hippocampus from the midline $(P=.0681)$ and the width of the right lateral ventricle $(P=.0524)$.

Visual analysis of MR images in FEBSTAT has previously demonstrated that HIMAL is present in an increased percentage of patients with FSE compared with SFS, but overall HIMAL was seen in only a small proportion of both groups. ${ }^{9}$ To determine whether the associations between medial temporal lobe morphology and seizure duration were due to the small subset of cases that were visually identified as having abnormal findings, we evaluated the relationship between temporal lobe morphology and seizure duration limited to cases that were visually identified as having normal findings, excluding those with HIMAL or increased T2 signal. Optimal cutoffs for distinguishing FSE versus SFS in these scans with visually normal findings are presented in Table 4 . We observed a relationship of multiple bilateral temporal lobe morphologic measurements to FSE in these subjects with visually normal findings (Table 4). In the multivariate model, FSE was associated with a lateral ventricle width of $>0.169 \mathrm{~cm}(P=.0078)$ and a normalized distance of the left hippocampus from the midline of $>1.51(P=.0315)$. FSE was associated with a right lateral ventricle width of $>0.202 \mathrm{~cm}(P<.0001)$, a normalized distance of the right hippocampus from the midline of $>1.52(P=.0245)$, right hippocampal height:width of $>0.6999(P=.0494)$, and a right hippocampal angle of $>185.5^{\circ}(P<.0038)$.

\section{DISCUSSION}

Hippocampal anomalies similar to HIMAL were initially described in association with agenesis of the corpus callosum and lissencephaly. ${ }^{6,17}$ HIMAL was subsequently identified as an isolated anomaly, and an association with epilepsy was suggested, ${ }^{7}$ though this association has been questioned. ${ }^{18}$ We previously described an increased incidence of HIMAL in children presenting with FSE, suggesting that developmental abnormalities of the temporal lobe are an important risk factor for prolonged febrile seizures. ${ }^{4,9}$ However, most subjects in the FEBSTAT study presenting with FSE and most patients with epilepsy more generally do not have HIMAL. The contribution of morphologic variation in the temporal lobe to FSE was therefore unclear in most subjects.

HIMAL consists of a constellation of individual morphologic components, any of which may be present to varying degrees and in varying combinations in an individual patient. We wished to determine whether the component features of HIMAL are indi- vidually associated with FSE and whether this association extends to subjects without the complete HIMAL constellation. We therefore performed quantitative measurements of temporal lobe morphologic features in the FEBSTAT cohort, focusing on features associated with HIMAL.

We found that multiple morphologic components of HIMAL independently predicted the clinical categorization of febrile seizures (SFS versus FSE) in the FEBSTAT cohort. We considered the possibility that inclusion of patients with HIMAL might confound these findings; therefore, we repeated the analysis after exclusion of patients with HIMAL or any other visible temporal lobe abnormality. The results of this subgroup analysis were essentially identical to those of the full cohort, indicating that the observed associations were not attributable to HIMAL or other visually apparent abnormalities. These findings suggest a model in which subtle bilateral temporal lobe morphologic abnormalities may predispose to FSE, and HIMAL represents a particular subset in which the abnormalities are visually evident. These findings are consistent with those in our prior reports that as a group, hippocampal volumes are slightly smaller in children with FSE and visually normal MRIs than in those with SFS. ${ }^{10}$ The current FEBSTAT data therefore suggest that there are subtle underlying abnormalities predisposing to FSE and that FSE is an insult that may result in hippocampal injury. ${ }^{10}$

HIMAL was almost exclusively left-sided in the FEBSTAT cohort, and we therefore expected that correlations between our morphologic measurements and prolonged seizures might be found predominantly on the left. In fact, we found the opposite of the expected lateralization: All 5 right-sided morphologic parameters were significant predictors of FSE in our multivariate model, whereas only 1 left-sided parameter (left temporal horn width) was a significant predictor. Unexpectedly, we have also observed a predominance of right-sided EEG abnormalities and acute hippocampal MR imaging findings in FEBSTAT. ${ }^{10,19}$ The subtle hippocampal volume abnormalities seen at baseline and at 1 year in the visually normal MRIs of children with $\mathrm{FSE}^{10}$ were also much more pronounced on the right. Data from animal models of FSE also suggest a predominance of right-sided abnormalities. ${ }^{20}$ These findings may indicate preferential involvement of the right temporal lobe in FSE based on an asymmetric incidence of predisposing anatomic features.

The significance of HIMAL as a risk factor for epilepsy is unclear and somewhat controversial. In part, this uncertainty reflects divergent conclusions of prior investigators regarding the frequency of HIMAL in the general population and patients with epilepsy, possibly reflecting divergent application of the subjective criteria that identify HIMAL. ${ }^{21,22}$ We found that the subjective identification of HIMAL by experienced readers can be predicted with high accuracy through quantitative measurement of the individual component features of HIMAL. The predictive value of individual features varies substantially, however. Increased width of the temporal horn of the lateral ventricle is shown to be the strongest predictor of HIMAL (a width of $>0.53$ $\mathrm{cm}$ predicts HIMAL with a sensitivity of $84.2 \%$ and a specificity of $86.1 \%$; adjusted odds ratio, 10.6). A decreased distance of the hippocampus from the midline and an increased hippocampal height:width ratio (ie, a rounder hippocampus) are also strong 
predictors. These features of temporal lobe anatomy are easily measured on coronal MR images and may provide a basis for improved consistency in the visual identification of HIMAL among interpreters. Angles of the hippocampus and collateral sulcus, in contrast, are not significant predictors of HIMAL in our multivariate model. While these features may be associated with HIMAL, the lack of a predictive value in our model suggests that variance of these features in the healthy population may be sufficiently high to render them less helpful in the identification of HIMAL.

The findings of this study suggest that subtle anatomic differences in temporal lobe morphology, not appreciable on visual inspection, are associated with and may predispose to prolonged febrile seizures. This suggestion is in keeping with a large body of prior evidence correlating subtle anatomic abnormalities found on automated, quantitative brain MR imaging analysis to various types of epilepsy. ${ }^{23}$ Application of automated analysis techniques to young children, including the FEBSTAT cohort, is complicated by rapid brain growth and progressive myelination during this period. Nevertheless, we anticipate that application of similar automated or semiautomated techniques may further define the nature and extent of anatomic abnormalities associated with prolonged febrile seizures.

The anatomic differences described in this article could, in theory, reflect either anomalous development of the temporal lobes or secondary degeneration resulting from pathologic processes. We consider an anomaly of primary development the more likely explanation because subjects in the FEBSTAT cohort were previously healthy children who were scanned shortly after their first febrile seizure. Most of the measurements included in this study (eg, distance of the hippocampus from the midline) are unlikely to change significantly in the acute postictal setting. The ratio of hippocampal height to width is an exception because it could, in theory, be affected by hippocampal edema. This is unlikely to be a significant confounding factor, however, because the relationship of an increased hippocampal height:width ratio to FSE was unchanged after exclusion of patients with overt evidence of hippocampal edema (increased T2-weighted signal).

Two limitations of the current study must be recognized. First, our results demonstrate an association between morphologic variation in the medial temporal lobes and the duration of febrile seizures, in particular with FSE. While patients presenting with FSE are at increased risk of later epilepsy, further observation of the FEBSTAT cohort will be required to determine which subjects develop epilepsy and, accordingly, whether the medial temporal lobe anatomic anomalies considered here are risk factors for epilepsy.

A second limitation of the current work is the use of only a single coronal image for our temporal lobe measurements. This was necessary given the time-intensive nature of manual measurements and the large size of the FEBSTAT cohort. Nevertheless, evaluation of the temporal lobe at a single anteroposterior location may result in underestimation of the incidence of anatomic anomalies of limited spatial extent. This limitation could be addressed with automated whole-brain analysis techniques as discussed above.

\section{CONCLUSIONS}

We found that the morphologic component features of HIMAL are independent predictors of FSE, even in the absence of HIMAL or other overt temporal lobe abnormalities. We conclude that a broader spectrum of subtly anomalous temporal lobe development exists that may confer increased risk for prolonged febrile seizures and resulting hippocampal injury. Those cases with HIMAL may represent a subset of this spectrum that is particularly amenable to visual identification. Further studies on other aspects of brain development in these children are planned.

\section{APPENDIX}

\section{FEBSTAT Study Team}

Montefiore and Jacobi Medical Centers, Bronx, New York: Shlomo Shinnar, MD, PhD (Principal Investigator); Jacqueline Bello, MD; William Gomes, MD, PhD; James Hannigan, RT; Sharyn Katz, R-EEGT, FASET; David Masur, PhD; Solomon L. Moshé, MD; Ruth Shinnar, RN, MSN; Erica Weiss, PhD.

Ann \& Robert Lurie Children's Hospital, Chicago, Illinois: Douglas Nordli, MD (site Principal Investigator); John Curran, MD; Leon G. Epstein, MD; Andrew Kim, MD; Diana Miazga; Julie Rinaldi, $\mathrm{PhD}$.

Columbia University, New York, New York: Dale Hesdorffer, $\mathrm{PhD}$ (site Principal Investigator); Stephen Chan, MD; Binyi Liu, MS; Yokasta Tineo, BA.

Duke University Medical Center, Durham, North Carolina: Darrell Lewis, MD (site Principal Investigator); Melanie Bonner, $\mathrm{PhD}$; Karen Cornett, BS, MT; William Gallentine, DO; James MacFall, PhD; James Provenzale, MD; Allen Song, PhD; James Voyvodic, PhD; Yuan Xu, BS.

Eastern Virginia Medical School, Norfolk, Virginia: L. Matthew Frank, MD (site Principal Investigator); Joanne Andy, RT; Terrie Conklin, RN; Susan Grasso, MD; Connie S. Powers, R-EEGT; David Kushner, MD; Susan Landers, RT; Virginia Van de Water, PhD.

International Epilepsy Consortium/Department of Biostatistics, Virginia Commonwealth University, Richmond, Virginia: Shumei Sun, PhD (site Principal Investigator); John M. Pellock, MD; Brian J. Bush, MSMIT; Lori L Davis, BA; Xiaoyan Deng, MS; Christiane Rogers; Cynthia Shier Sabo, MS.

Mount Sinai Medical Center, New York, New York: Emilia Bagiella, PhD.

Virginia Commonwealth University, Richmond, Virginia: John M. Pellock, MD (site Principal Investigator); Tanya Brazemore, R-EEGT; James Culbert, PhD; Kathryn O'Hara, RN; Syndi Seinfeld, DO; Jean Snow, RT-R.

Additional collaborators: Joan Conry, MD; Children's National Medical Center, Safety Monitor; Tracy Glauser, MD; Cincinnati Children's Medical Center, Genomics; Jeffrey L. Noebels, MD, PhD; Baylor College of Medicine, Genetics.

Disclosures: William A. Gomes_RELATED: Grant: National Institute of Neurological Disorders and Stroke (NS43209)*; UNRELATED: Grants/Grants Pending: Gerber Foundation.* Shlomo Shinnar-RELATED: Grant: National Institutes of Health,* Comments: funded by grants NS 43209 from National Institute of Neurological Disorders and Stroke (Principal Investigator: S. Shinnar) and HD 36867 from the National Institute of Child Health and Human Development (Principal Investigator: D.C. Hesdorffer); UNRELATED: Consultancy: Acorda Therapeutics, Neurelis, UpsherSmith Laboratories, Xeris Pharmaceuticals, Comments: consulting fees on preclinical 
development of drugs for treatment of acute repetitive seizures; not directly related to this work but included as related to treatment of seizures; Royalties: royalties on the book Febrile Seizures edited by Baram and Shinnar, Academic Press $2002(<\$ 100$ per annum for the past 5 years). Dale C. Hesdorffer-RELATED: Grant: There has been funding from National Institute of Neurological Disorders and Stroke, though I was not part of that grant. The funding no longer exists, even during the time that the data submitted were analyzed; UNRELATED: Board Membership: Acorda Therapeutics, Upsher-Smith Laboratories, Comments: Both are advisory boards; Consultancy: Cyberonics, Mount Sinai Medical Center Rehabilitation; Grants/Grants Pending: Centers for Disease Control and Prevention, National Institute of Neurological Disorders and Stroke, The Patient-Centered Outcomes Research Institute, Finding a Cure for Epilepsy and Seizures, Citizens United for Research in Epilepsy, Epilepsy Study Consortium; Travel/Accommodations/Meeting Expenses Unrelated to Activities Listed: travel reimbursed from the International League Against Epilepsy, where I serve on several task forces in the Epidemiology Commission and in other areas; Other: Epilepsia, Associate Editor. Emilia Bagiella—RELATED: Grant: National Institute of Neurological Disorders and Stroke, ${ }^{\star}$ Comments: subcontract to Dr Shinnar's grant. Darrell V. Lewis-RELATED: Grant: National Institute of Neurological Disorders and Stroke, ${ }^{*}$ Comments: grant support for the FEBSTAT study. Stephen Chan-RELATED: Grant: National Institute of Neurological Disorders and Stroke, Comments: supported by grant R01 NS-043209 (to S. Shinnar) from the National Institutes of Health. Ruth C. Shinnar-RELATED: Grant: National Institute of Neurological Disorders and Stroke (NS43209).* James MacFall—RELATED: Grant: National Institute of Neurological Disorders and Stroke*; Support for Travel to Meetings for the Study or Other Purposes: National Institute of Neurological Disorders and Stroke*; UNRELATED: Grants/Grants Pending: National Institute of Neurological Disorders and Stroke. * John M. Pellock—RELATED: Grant: National Institute of Neurological Disorders and Stroke*; UNRELATED: Board Membership: Acorda Therapeutics, Upsher-Smith Laboratories; Consultancy: Acorda Therapeutics, Upsher-Smith Laboratories. Douglas R. Nordli Jr-RELATED: Grant: National Institutes of Health,* Comments: I participated as an investigator in this National Institutes of Healthsponsored project for FEBSTAT. Ludwig Frank—RELATED: Grant: National Institutes of Health-sponsored grant, "FEBSTAT"*; Support for Travel to Meetings for the Study or Other Purposes: National Institute of Neurological Disorders and Stroke, Comments: study meeting reimbursement. Solomon L. Moshé-RELATED: Grant: National Institute of Neurological Disorders and Stroke*; UNRELATED: Grants/ Grants Pending: National Institute of Neurological Disorders and Stroke, ${ }^{\star}$ Citizens United for Research in Epilepsy, ${ }^{*}$ Department of Defense, ${ }^{*}$ Rett Syndrome Research Trust, ${ }^{\star}$ Comments: funded to carry out various projects in epilepsy; Payment for Lectures (including service on Speakers Bureaus): Eisai, UCB; Patents (planned, pending or issued): animal model of infantile spasms; Royalties: Elsevier. Shumei SunRELATED: Grant: National Institute of Neurological Disorders and Stroke*; UNRELATED: Grants/Grants Pending: National Institutes of Health.* * Money paid to the institution.

\section{REFERENCES}

1. Shinnar S. Febrile seizures and mesial temporal sclerosis. Epilepsy Curr 2003;3:115-18 CrossRef Medline

2. Hesdorffer DC, Shinnar S, Lewis DV, et al; FEBSTAT Study Team. Design and phenomenology of the FEBSTAT study. Epilepsia 2012; 53:1471-80 CrossRef Medline

3. Hesdorffer DC, Shinnar S, Lewis DV, et al; Consequences of Prolonged Febrile Seizures in Childhood (FEBSTAT) Study Team. Risk factors for febrile status epilepticus: a case-control study. J Pediatr 2013;163:1147-51.e1 CrossRef Medline

4. Chan S, Bello JA, Shinnar S, et al; FEBSTAT Study Team. Hippocampal malrotation is associated with prolonged febrile seizures: results of the FEBSTAT study. AJR Am J Roentgenol 2015;205:1068-74 CrossRef Medline
5. Humphrey T. The development of the human hippocampal fissure. J Anat 1967;101:655-76 Medline

6. Kier EL, Kim JH, Fulbright RK, et al. Embryology of the human fetal hippocampus: MR imaging, anatomy, and histology. AJNR Am J Neuroradiol 1997; 18:525-32 Medline

7. Barsi P, Kenéz J, Solymosi D, et al. Hippocampal malrotation with normal corpus callosum: a new entity? Neuroradiology 2000;42: 339-45 CrossRef Medline

8. Lehéricy S, Dormont D, Sémah F, et al. Developmental abnormalities of the medial temporal lobe in patients with temporal lobe epilepsy. AJNR Am J Neuroradiol 1995;16:617-26 Medline

9. Shinnar S, Bello JA, Chan S, et al; FEBSTAT Study Team. MRI abnormalities following febrile status epilepticus in children: the FEBSTAT study. Neurology 2012;79:871-77 CrossRef Medline

10. Lewis DV, Shinnar S, Hesdorffer DC, et al; FEBSTAT Study Team. Hippocampal sclerosis after febrile status epilepticus: the FEBSTAT study. Ann Neurol 2014;75:178-85 CrossRef Medline

11. Maytal J, Shinnar S. Febrile status epilepticus. Pediatrics 1990;86: 611-16 Medline

12. Lewis DV, Barboriak DP, MacFall JR, et al. Do prolonged febrile seizures produce medial temporal sclerosis? Hypotheses, MRI evidence and unanswered questions. Prog Brain Res 2002;135:263-78 CrossRef Medline

13. VanLandingham KE, Heinz ER, Cavazos JE, et al. Magnetic resonance imaging evidence of hippocampal injury after prolonged focal febrile convulsions. Ann Neurol 1998;43:413-26 CrossRef Medline

14. Hesdorffer DC, Chan S, Tian H, et al. Are MRI-detected brain abnormalities associated with febrile seizure type? Epilepsia 2008;49: 765-71 CrossRef Medline

15. National Institutes of Health. Febrile Seizures: Consensus Development Conference Summary. Vol 3. Bethesda: National Institutes of Health; 1980:1-11

16. Youden WJ. Index for rating diagnostic tests. Cancer 1950;3:32-35 Medline

17. Baker LL, Barkovich AJ. The large temporal horn: MR analysis in developmental brain anomalies versus hydrocephalus. AJNR Am J Neuroradiol 1992;13:115-22 Medline

18. Raininko R, Bajic D. "Hippocampal malrotation": no real malrotation and not rare. AJNR Am J Neuroradiol 2010;31:E39; author reply E40 CrossRef Medline

19. Nordli DR Jr, Moshé SL, Shinnar S, et al; FEBSTAT Study Team. Acute EEG findings in children with febrile status epilepticus: results of the FEBSTAT study. Neurology 2012;79:2180-86 CrossRef Medline

20. Dubé $\mathrm{CM}$, Zhou JL, Hamamura $M$, et al. Cognitive dysfunction after experimental febrile seizures. Exp Neurol 2009;215:167-77 CrossRef Medline

21. Gamss RP, Slasky SE, Bello JA, et al. Prevalence of hippocampal malrotation in a population without seizures. AJNR Am J Neuroradiol 2009;30:1571-73 CrossRef Medline

22. Bajic D, Canto Moreira N, Wikström J, et al. Asymmetric development of the hippocampal region is common: a fetal MR imaging study. AJNR Am J Neuroradiol 2012;33:513-18 CrossRef Medline

23. Memarian N, Thompson PM, Engel J Jr, et al. Quantitative analysis of structural neuroimaging of mesial temporal lobe epilepsy. Imaging Med 2013;5 CrossRef Medline 